\title{
A NOVEL ACTIVATED CARBON INJECTION METHOD TO ENHANCE PCDD/FS REMOVAL EFFICIENCY IN FLUE GAS FROM A MEDICAL WASTE INCINERATOR IN SHANGHAI, CHINA
}

\author{
QIANG, N. - HE, J. - MIAO, H. - XIE, L. - LIU, T.* - CAO, Y. - LI, Z. \\ Institute for Environmental Science and Technology, Tongji University \\ 200092 Shanghai, China \\ *Corresponding author \\ e-mail: liutao45@163.com; phone: +86-21-6598-1926; fax: +86-021-6598-1926
}

(Received 24 $4^{\text {th }}$ Jan 2018; accepted $25^{\text {th }}$ Apr 2018)

\begin{abstract}
To reach the emission standard of PCDD/Fs, different influencing factors of removal efficiency of traditional activated carbon injection (ACI) process were considered in this research. Besides, a modified activated carbon injection (ACI) process was developed to improve the removal efficiency of PCDD/Fs. Results showed that removal efficiency of PCDD/Fs using activated carbon A (fitted the dioxin molecular size) was higher than using B (commercially available powder activated carbon) with the same dosage of $1000 \mathrm{mg} / \mathrm{m}^{3}$. And contact time extended to $8 \mathrm{~s}$ was a better choice. Vapor pressures of $\mathrm{PCDD} / \mathrm{Fs}$ congeners influenced the gas/particle partitioning of PCDD/Fs removal efficiencies. The modified ACI - pulse ACI process demonstrated higher dioxins removal efficiency ( 99.6\%) than the traditional method due to the increased thickness of carbon layer and total residence time of carbon.
\end{abstract}

Keywords: pulse activated carbon injection, dioxins, carbon species, dosage, contact time, vapor pressure

\section{Introduction}

The incineration of medical waste discharges large quantity of polychlorinated dibenzo-p-dioxins and polychlorinated dibenzofurans (PCDD/Fs), widely known as dioxins. Dioxins are potentially toxic chemicals with serious health hazard even at extremely low doses. The majority of dioxins tend to travel long distances before falling to earth with rainfall or settling as particle (Singh and Prakash, 2007). Additionally, dioxins are extremely persistent with an estimated half-life of 7-11 years in humans (Schecter et al., 2006). Currently, activated carbon injection (ACI) in combination with bag filter has been found to be an effective alternative to the conventional process for the removal of vapor-phase dioxins at low concentrations in the flue gas from waste incinerator (Abad et al., 2003; Gunes et al., 2015; Chi et al., 2008). However, the low attainment rate of the PCDD/Fs discharge from medical waste incineration flue gas in the whole country indicates that the traditional ACI is far less efficient to meet the national requirement $0.5 \mathrm{TEQ} \mathrm{ng} / \mathrm{m}^{3}$ (MEP, 2001). Especially in Shanghai, the new emission standard of $0.1 \mathrm{TEQ} \mathrm{ng} / \mathrm{m}^{3}$ is much stricter. Thus, there is an urgent need for a more efficient PCDD/Fs removal method for old projects transformation and new projects construction. Besides, the use of the adsorbents is less efficient and may lead to an increase in the total amount of emissions from the incineration plant (flue gas + cyclone ash + reacted ash) (Chang and Lin, 2001). Another issue is the reliability of results on dioxins formation based on laboratory studies, which depends on the use of model compounds (Debecker et al., 2011). Several factors influence the removal efficiency of ACI and bag filter system, including gas/particle partitioning of PCDD/Fs 
(Chang et al., 2002), species and dosage of activated carbon (AC) (Abad et al., 2003; Kim et al., 2007; Tejima et al., 1996), injection rate (Gunes et al., 2015), contact time of activated carbon and PCDD/Fs (Karademir et al., 2004), gas/particle partitioning (Karademir et al., 2004), and injection method among others. Tejima et al. (1996) reported that the removal efficiency of $\mathrm{PCDD} / \mathrm{Fs}$ could reach over $99 \%$ with activated carbon dosage of 50-100 mg/m $\mathrm{m}^{3}$. Similar results were reported by Abad et al. (2003) and Everaert et al. (2003). Gunes et al. (2015) reported that the optimum ACI rate for PCDD/Fs was $66 \mathrm{mg} / \mathrm{m}^{3}$ with removal efficiency was $97 \%$ and no significant difference in efficiency was observed at ACI rate of $197 \mathrm{mg} / \mathrm{m}^{3}$. Some studies have reported the use of a double-bag activated carbon adsorption process on the basis of the traditional ACI process with a single bag for the removal of PCDD/Fs in a medical waste incinerator system (Kim et al., 2007; Mckay, 2002; Chen et al., 2014; Lin et al., 2008). Though higher removal efficiency was achieved using less amount of activated carbon, the capital and operating costs increased significantly. Li et al. (2008) added a biosolution (NOE-7F) to the raw materials, which inhibited PCDD/F formation and combining both ACI and NOE-7F had a high potential for practical application. By the addition of NOE-7F in the stack flue gas, the fraction of total PCDD/F was reduced by 92.4\%, which was not high enough to meet the EU emission standard. Ooi et al. (2008) reported the removal of vapor phase PCDD/Fs by adsorbing into plastics instead of activated carbon and the removal efficiency was over $99 \%$. The experiments, however, were conducted in an electric arc furnace steel plant. There have been no reports so far about modification of ACI method as applied to medical waste incinerators.

Therefore, this paper introduces the very first modified injection method for PCDD/Fs removal examined in a commercial-scale medical waste incineration facility in Shanghai and evaluates its efficiency. Influences of traditional injection method on PCDD/Fs removal are also examined for comparison, including species and dosage of activated carbon, contact time, and gas/particle partitioning.

\section{Materials and methods}

\section{Full-scale medical waste incinerator}

The medical waste incinerator researched is located in Shanghai, China. The dealing capacity of the incinerator plant is 2400 2500 metric ton/day and operates 300 days per year. The incinerator has a two-stage combustion system consisting of a rotary kiln of $4.3 \mathrm{~m}$ diameter. The temperatures of the rotary kiln head and kiln are 870 890 ${ }^{\circ} \mathrm{C}$ and $1020 \sim 1050{ }^{\circ} \mathrm{C}$ separately. The original air pollution control system included quench tower, dry-type reactor, traditional ACI, bag filter, and wet scrubbing tower, and the efficiency was $97.5 \%$, which met the Chinese emission standard of dioxins (0.5 TEQ $\left.\mathrm{ng} / \mathrm{m}^{3}\right)$. However, to reach the Shanghai limit $\left(0.1 \mathrm{TEQ} \mathrm{ng} / \mathrm{m}^{3}\right)$, the ACI process needs to be retrofitted. Besides, $\mathrm{SO}_{2}$ and $\mathrm{HCl}$ are captured by powdered $\mathrm{Ca}(\mathrm{OH})_{2}$ injection.

Activated carbon A used in the test fitted the dioxin molecular size (the average relative molecular size of dioxins and furans is 10 angstroms $(1 \mathrm{~nm})$ ). Activated carbon $\mathrm{B}$ is commercially available powder activated carbon. Their characteristics are presented in Table 1.

The International Theoretical and Applied Chemistry Federation has defined the pore size as follows: small pores: $<2 \mathrm{~nm}$ in diameter, middle pores: $2-5 \mathrm{~nm}$ in diameter, large pores: $>50 \mathrm{~nm}$ in diameter. Iodine value is an index reflecting the level of iodine adsorption in water, which shows the micro pore volume of activated carbon. Molasses 
( $\mathrm{mg}$ ) is the number of key indicators to measure the sugar decolorization, and shows the number of middle pores and large pores.

Table 1. Characteristics of the tested AC

\begin{tabular}{c|c|c}
\hline Species & Activated carbon A (GL50) & Activated carbon B \\
\hline Iodine value & 700 & 1100 \\
Molasses $(\mathrm{mg})$ & 525 & 200 \\
Surface area $(\mathrm{m} / \mathrm{g})$ & 800 & 1225 \\
Bulk density $(\mathrm{kg} / \mathrm{m})$ & 490 & 250 \\
Particle size D50 $(\%)$ & 20 & 10 \\
Acid-base properties & Alkaline & Alkaline \\
\hline
\end{tabular}

\section{Description of the Pulse ACI Unit}

Activated carbon injection is an important approach to control dioxins in flue gas. Traditional ACI process injects activated carbon continuously for cleaning the flue gas (Abad et al., 2003; Gunes et al., 2015). Since the activated carbon adsorption process is carried out at high temperature and humidity, and at a wide concentration range of dioxins in the flue gas, the equilibrium adsorption capacity and contact time is limited by the thermodynamics. Therefore, to achieve a dioxins removal efficiency of over $99 \%$, a modified ACI technology is needed in addition to using the increased amount of activated carbon and contact time.

The AC injection method was modified in this study and is known as pulse activated carbon injection method. During the bag cleaning cycle, first dose of large amount of activated carbon was injected in a short time and then a small amount of AC was added steadily. The whole process was carried out periodically. Since the diagram of the activated carbon dosage and time represents like a pulse signal, the method is termed as pulse ACI. The improved method does not increase the amount of activated carbon dosage needed. The bag cleaning cycle is one hour. During the bag cleaning cycle, there were two dosage stages. In the first stage, it took $30 \mathrm{~s}$ to dose $50 \%$ of the total activated carbon dosage. In the next stage, it took the one hour to dose the remaining 50\% of the total activated carbon continuously and uniformly. The pulse method is shown in Figure 1. The dotted line represents the traditional method while the solid line represents the pulse method. Keeping the total activated carbon dosage same in both methods, the areas of the shadow in the Figure 1 are equal in one bag cleaning cycle.

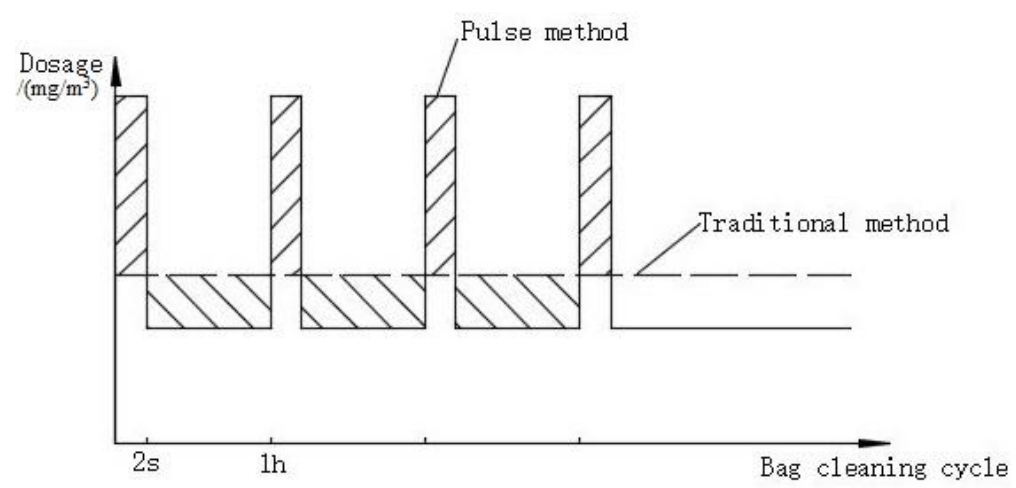

Figure 1. Pulse injection method of AC in medical waste incinerator, Shanghai, China 


\section{Sampling and analyses}

Flue gas samples were taken from four sampling points and the locations of flue gas sampling points are shown in Figure 2. The emission of PCDD/Fs in flue gas was measured simultaneously at four sampling points.

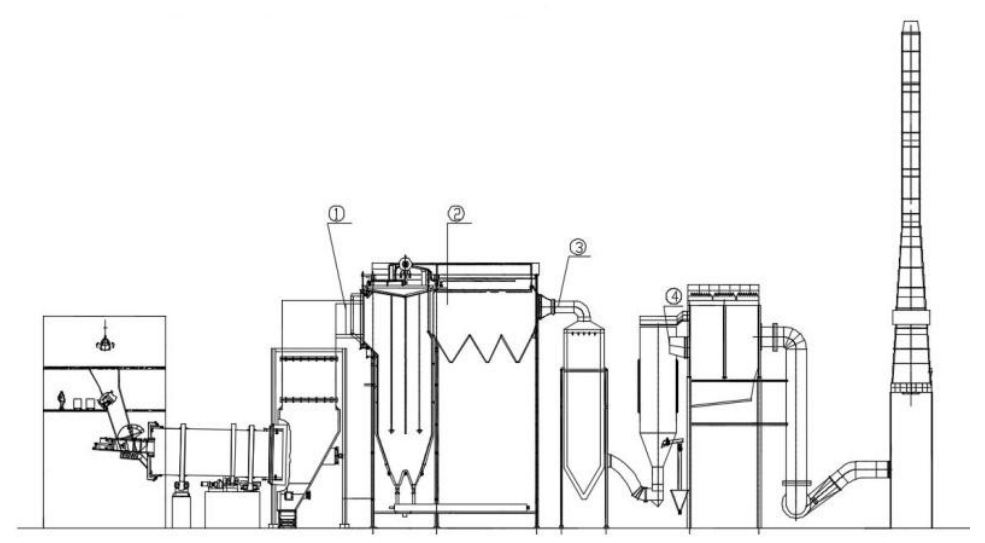

Figure 2. Sampling points: (1) the post-combustion chamber outlet; (2) the high temperature point in the waste heat boiler (entrance point); (3) the waste heat boiler outlet; (4) the bag filter inlet

Sampling procedures are as follows. First, the sampling device was installed according to European Standard Protocols EN1948-1 and the air tightness of the sampling system was checked. Then the sampling tube was inserted into the flue sampling point, and the sampling hole was closed. And then the sampling nozzle was aligned with the gas flow direction, and the sampling pump was started to adjust the sampling rate. During the sampling period, when the pressure and temperature changed greatly, it was necessary to adjust the flow rate in time. If the resistance of the filter cylinder increased too large to keep a constant sampling speed, the filter cartridge should be replaced and then continue to sample. In the process of sampling, special attention was paid to keeping the gas phase adsorption column out of light and below $30^{\circ} \mathrm{C}$. After sampling, the sampling pump was stopped and the sampling tube was drawn out at the same time. Besides, time, cumulative flow and other parameters were recorded. At last, the sampling device was removed without light and the cartridge was also removed and wrapped with aluminum foil. The sampling tubes and connecting pipes were washed with toluene. Washing liquid and condensed water were saved in brown reagent bottle.

Main apparatus and equipment used in field sampling (shown in Fig. 3) include four sets of quartz cooling, buffer bottle, adsorption bottle, and so on (self-designed); four ice baths with circulating pump sampling box; three sampling device lifting frames; one aneroid barometer; digital temperature and humidity meter (Finland HM34); digital pressure gauges (German MUR DM9100); S-type Pibtot's tubes and hot bulb anemometers.

Analysis was conducted by the Belgian SGS company. The analytical method was US EPA Method 23 (US EPA1995). Identification and quantification of PCDD/Fs were performed by HRGC/HRMS using a 7890 Series gas chromatograph (Agilent, USA) and AutoSpec Premier (Waters). 


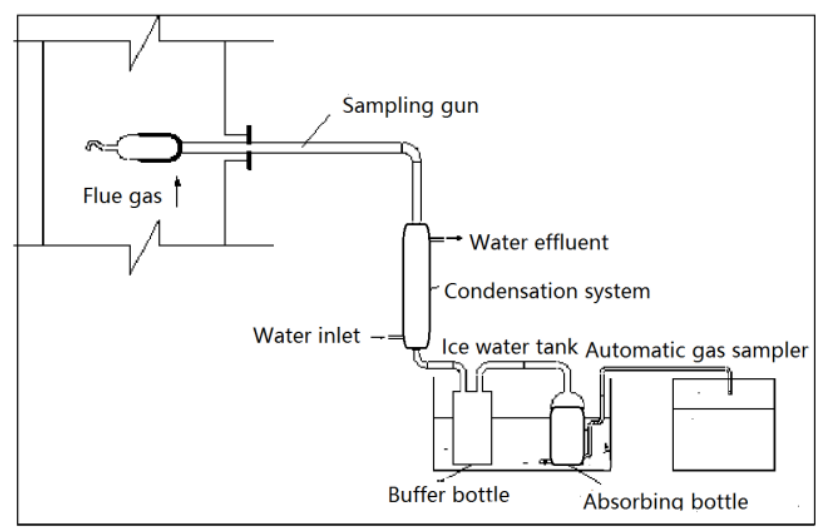

Figure 3. Flow chart of sampling system

The results of each selected influencing factors of PCDD/Fs removal efficiency were statistically analyzed. If the factor had significant influence on PCDD/Fs removal efficiency, the probability in the result of variance analysis must be less than 0.05 or at least equal to $0.05(\mathrm{P} \leq 0.05)$.

\section{Results and discussion}

\section{PCDD/Fs removal efficiencies of conventional ACI process}

\section{Effect of activated carbon types and dosage on PCDD/Fs removal efficiencies}

ACI method involves injecting a certain amount of solid adsorbent into the flowing gas before bag filter and then separating the adsorbent before discharging the gas (Karademir et al., 2004). ACI technique transfers dioxins from gas phase to solid phase and further treatment (such as bag filter) is usually required. As discussed above, activated carbon type and dosage are two important factors that affect the removal efficiency of dioxins. These two factors were examined in this study. Both activated carbon A and activated carbon B were added at the entrance of the bag to study the effect of activated carbon types on dioxins removal. The dosages of activated carbon $\mathrm{A}$ and $B$ were $100 \mathrm{mg} / \mathrm{m}^{3}$ and $1000 \mathrm{mg} / \mathrm{m}^{3}$. The results are summarized in Table 2.

It can be seen from Table 2 that ACI technology showed high removal efficiency for PCDD/Fs. ACI system and bag filter are used to remove the gas phase and particle phase PCDD/Fs, respectively (Gunes et al., 2015). Since PCDD/Fs compounds in gas phase comprised of the majority of the pollutants tested, adsorption of gas phase compounds on the $\mathrm{AC}$ and then removal of $\mathrm{AC}$ and compounds in particle phase on filter was proved to be an effective way of removal of total PCDD/Fs in flue gas instead of using bag filter alone.

The addition of same dosage (i.e., $100 \mathrm{mg} / \mathrm{m}^{3}$ ) of activated carbon, the average removal efficiency of activated carbon A was much higher (92\%) than that of activated carbon B (82\%). Abad et al. (2003) reported 92-96\% PCDD/Fs removal efficiency at activated carbon dosage of $100 \mathrm{mg} / \mathrm{m}^{3}$. Everaert et al. (2003) also found the removal efficiency of $93-94 \%$ at activated carbon dosage of $50-100 \mathrm{mg} / \mathrm{m}^{3}$ in ACI. However, the results showed that the $\mathrm{PCDD} / \mathrm{Fs}$ removal efficiency at this dosage is still very low to meet the strict emission requirements of 0.1 TEQ $\mathrm{ng} / \mathrm{m}^{3}$. 
Table 2. Removal efficiencies of PCDD/F congeners by different AC species and dosage

\begin{tabular}{c|c|c|c|c}
\hline \multirow{2}{*}{ Congener } & \multicolumn{4}{|c}{ Removal efficiency $\mathbf{( \% )}$} \\
\cline { 2 - 4 } & $\begin{array}{c}\mathbf{A} \\
\mathbf{1 0 0} \mathbf{~ m g / \mathbf { m } ^ { 3 }}\end{array}$ & $\begin{array}{c}\mathbf{A} \\
\mathbf{1 0 0 0} \mathbf{~ m g} / \mathbf{m}^{\mathbf{3}}\end{array}$ & $\begin{array}{c}\mathbf{B} \\
\mathbf{1 0 0} \mathbf{~ m} / \mathbf{m}^{\mathbf{3}}\end{array}$ & $\begin{array}{c}\mathbf{B} \\
\mathbf{1 0 0 0} \mathbf{~ m g} / \mathbf{m}^{\mathbf{3}}\end{array}$ \\
\hline 2378-TCDF & 93.7 & 97.5 & 88.8 & 96.6 \\
12378-PeCDF & 95.2 & 96.3 & 84.8 & 94.9 \\
23478-PeCDF & 92.5 & 96.0 & 86.4 & 92.5 \\
123478-HxCDF & 95.5 & 96.0 & 87.1 & 94.2 \\
123678-HxCDF & 95.9 & 96.5 & 87.7 & 91.6 \\
234678-HxCDF & 93.2 & 95.8 & 82.4 & 92.7 \\
123789-HxCDF & 93.4 & 93.8 & 87.5 & 89.1 \\
1234678-HpCDF & 91.6 & 96.3 & 88.1 & 90.7 \\
123478-HpCDF & 90.6 & 95.8 & 81.7 & 90.1 \\
OCDF & 85.5 & 96.1 & 82.6 & 87.1 \\
2378-TCDD & 85.1 & 94.2 & 81.2 & 79.2 \\
12378-PeCDD & 93.0 & 94.6 & 89.0 & 91.8 \\
\cline { 1 - 1 } 123478-HxCDD & 94.1 & 95.7 & 86.3 & 90.8 \\
123678-HxCDD & 94.1 & 96.3 & 89.4 & 90.5 \\
123789-HxCDD & 92.6 & 95.3 & 87.1 & 89.1 \\
1234678-HpCDD & 90.1 & 97.1 & 87.8 & 89.7 \\
OCDD & 84.2 & 97.9 & 85.6 & 88.2 \\
PCDD/Fs & 89.5 & 96.0 & 86.6 & 92.1 \\
\hline
\end{tabular}

Single factor analysis of the data of these two types of AC had P-value of $1.22 \times 10^{-5}$ $(<0.05)$, indicating that AC types has a significant effect on the PCDD/Fs removal efficiency. Since activated carbon A has higher specific surface area and pore size, which is ideal for the removal of dioxins, it has higher adsorption capacity and removal efficiency.

Higher dosage of activated carbon was needed to achieve higher removal efficiency. The dosages of the activated carbon A and B were both increased from 100 to $1000 \mathrm{mg} / \mathrm{m}^{3}$. The single factor analysis of the data for activated carbons A and B had Pvalues of $2.15 \times 10^{-5}$ and 0.000347 , respectively, which are far below 0.05 , indicating that the dosage also has a significant effect on the removal efficiency. For both types of activated carbon, removal efficiency improved with increasing the dosage. However, the increase in efficiency was not obvious. For activated carbon A, removal efficiency of low and high chlorine content congeners increased more compared to medium chlorine content congeners. For activated carbon B, the efficiency showed variability with the increase of the chlorine atom number. For the congeners with same number of chlorine atoms, the efficiency differed with the position of chlorine atom substituted and differed from dioxins to furans, especially 2,3,7,8-TCDD and 2,3,7,8-TCDF, which showed significant difference. Although activated carbon A at $1000 \mathrm{mg} / \mathrm{m}^{3}$ had the highest removal efficiency for all congeners, the advantage was not significant; likely due to saturation of its adsorption capacity. Since the injection point of activated carbon at the batch experiment was at the inlet of the bag filter, the contact time of the flue gas and activated carbon was limited, which could have resulted overall low removal efficiency $(\sim 96 \%)$. 
Since the flue gas generation rate from medical waste incinerator is significantly less than that from large domestic waste incinerator, the dosage of the activated carbon A was increased to $1000 \mathrm{mg} / \mathrm{m}^{3}$ which resulted in increase in the removal efficiency of PCDD/Fs from 90 to $96 \%$. However, the increase of PCDD/Fs removal efficiency was not always consistent with the increased dosage of activated carbon. Everaert et al. (2003) reported no significant change in removal efficiency at injection rates over $200 \mathrm{mg} / \mathrm{m}^{3}$. Chang et al. (2001) expressed that the higher AC injection would not significantly increase the dioxin removal efficiency when the injected AC concentration was over $50 \mathrm{mg} / \mathrm{Nm}^{3}$ and a large amount of activated carbon would lead to an increase in total dioxin emissions (flue gas + cyclone ash + reacted ash). Gunes et al. (2015) also reported no significant difference in removal efficiency at $197 \mathrm{mg} / \mathrm{m}^{3}$ and $66 \mathrm{mg} / \mathrm{m}^{3} \mathrm{AC}$ injection rate, and the efficiency decreased at $332 \mathrm{mg} / \mathrm{m}^{3}$ of AC injection rate. Although the efficiency greatly improved at $1000 \mathrm{mg} / \mathrm{m}^{3}$ of $\mathrm{AC}$ dosage, it still failed to consistently meet the EU 2000 guidelines for dioxin emission standards. Considering the dosage of $1000 \mathrm{mg} / \mathrm{m}^{3}$ was extremely high, no further test was conducted at higher dosage of activated carbon from the thermodynamics stand point. Similarly, increasing the dosage of activated carbon B by 10 -folds could only reduce the dioxin emissions by about $50 \%$ (from 0.15 to $0.08 \mathrm{TEQ} \mathrm{ng} / \mathrm{m}^{3}$ ). No further significant improvement was achieved at higher dosage of activated carbon injection. Thus, there is a need to explore advanced technology to improve the removal efficiency of the flue gas contaminants.

\section{Effect of contact time on PCDD/Fs removal efficiencies}

Contact time or residence time, is very important factor affecting adsorption of organic compounds on activated carbon (Karademir et al., 2004). However, only very limited studies has explored the effect of contact time on adsorption of organic compounds on activated carbon at full-scale medical waste incinerator. Since the concentration of dioxins in flue gas is at TEQ $\mathrm{ng} / \mathrm{m}^{3}$ level, the driving force for the mass transfer from flue gas to activated carbon is relatively small compared to emissions of other pollutants at significantly high concentrations. In order to improve the mass transfer rate, a reasonable increase in contact time of activated carbon and flue gas becomes an important factor to increase the adsorption rate and efficiency. The previous injection point was at the entrance of the bag filtration and the average contact time was less than $2 \mathrm{~s}$. After modification of the injection point to the dry fluidized bed, the average contact time was more than $8 \mathrm{~s}$. The removal efficiency was compared under the same injection and burning conditions as shown in Figure 4. The injected activated carbon types and dosage were specialized ones with $1000 \mathrm{mg} / \mathrm{m}^{3}$.

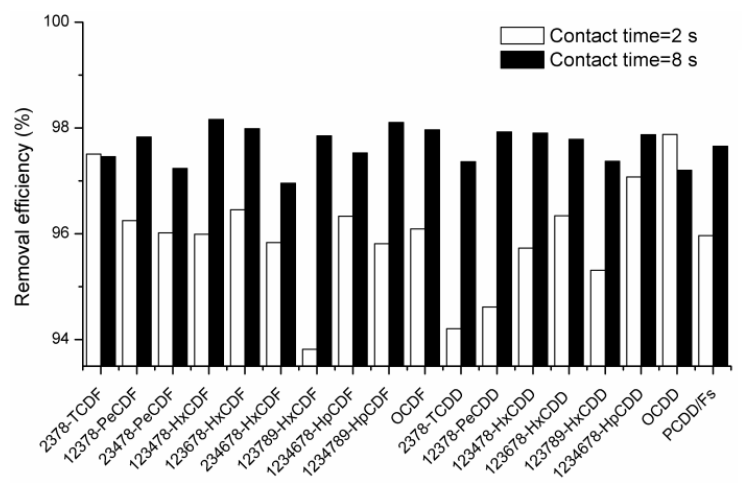

Figure 4. Removal efficiencies of PCDD/F congeners through different contact time 
Figure 4 shows that removal efficiency of PCDD/Fs improved from 96 to $98 \%$. The removal efficiency of 17 congeners except 2,3,7,8-TCDF and OCDD increased. The highest increase in removal efficiency was from 93.8 to $97.9 \%$ for $1,2,3,7,8,9-\mathrm{HxCDF}$ and the lowest increase was from 97.1 to $97.9 \%$ for $1,2,3,4,6,7,8-\mathrm{HpCDD}$. Although the increase in contact time improved the removal efficiency, the removal efficiency was still below the emission standard. Thus, modified ACI process was examined to improve the efficiency as discussed in the following section.

\section{Effect of activated carbon on the removal of dioxins in the gas and solid phases}

The distribution of dioxins in gas and solid phases is a very important factor for dioxins removal. The effect of activated carbon on the removal of dioxins in gas phase and solid phase was studied in order to further study the improvement of the active carbon injection method. The injection condition was activated carbon A dosage of $1000 \mathrm{mg} / \mathrm{m}^{3}$ at the dry fluidized bed and the burning condition was discussed in section 2.1. The results are presented in Figure 5.

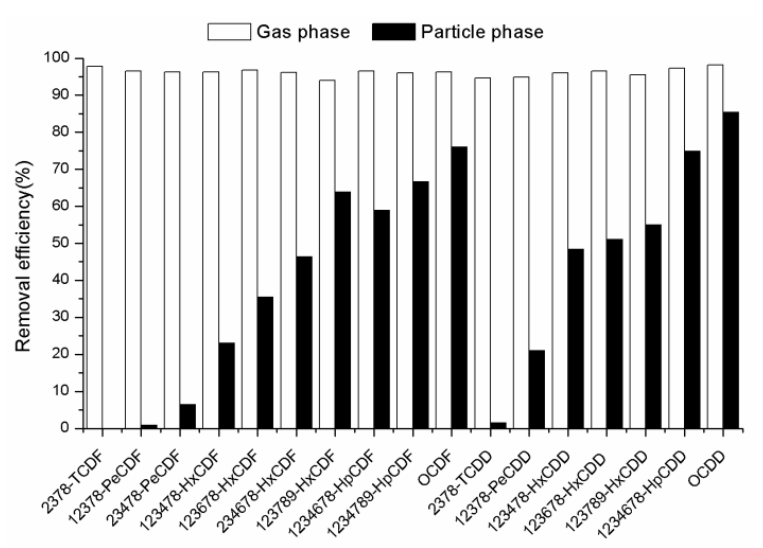

Figure 5. Removal efficiencies of PCDD/F congeners for gas and particle phase

Activated carbon has high removal efficiency of dioxins in the flue gas. The removal efficiency of PCDD/Fs in flue gas was $97.1 \%$. But the removal efficiency was much lower for the particle state $(\sim 75.5 \%)$, indicating that ACI was more effective to treat dioxins in gas phase. The removal efficiencies of particulate dioxins and PCDD/Fs with higher molecular weight were higher than that with lower molecular weight. The increase in removal efficiency showed a linear trend with increase in molecular weight, which indicates that part of PCDD/Fs with low molecular weight was in the nanometer aerosol state leading to low efficiency of traditional ACI process. However, considering that the proportion of dioxins in the gas phase was more than $98 \%$, gaseous dioxins were the main target of the dioxin emission control.

From other aspect, the removal efficiencies of both low chlorinated and high chlorinated congeners in gas phase were high in PCDD and PCDF, while the efficiencies of congeners in particle phase increased with the increase of chlorine content of both PCDD and PCDF. This is mainly attributed to different vapor pressures of congeners and adsorption capacity of activated carbon for dioxins in gas and solid phases (Chang et al., 2002). Less chlorinated congeners have higher vapor pressure and tend to exit in gas phase, which are more likely to be adsorbed by activated carbon 
(Gunes et al., 2015). On the other hand, higher chlorinated congeners tend to exist in solid phase due to their lower vapor pressures. Hence, the removal efficiency of less chlorinated congeners in gas phase is higher than that in the solid phase, while the removal efficiencies of higher chlorinated congeners show the opposite trend. With the increase in chlorine content, the removal efficiencies of congeners in particle phase increased because more congeners tend to exist in particle phase. Figure 6 shows the average efficiencies of the three tests for PCDD/F homologues and their relationship with the vapor pressure $(\log \mathrm{P})$ at $25^{\circ} \mathrm{C}(\mathrm{Li}$ et al., 2008).

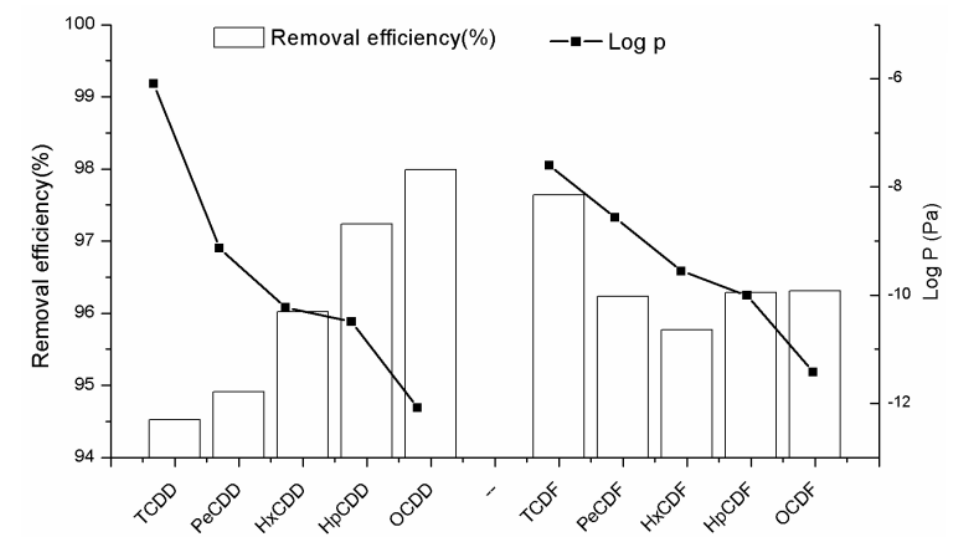

Figure 6. Average removal efficiencies of PCDD/F homologues

Figure 6 shows that as chlorination level of PCDD homologue increased, removal efficiencies increased while vapor pressure declined. For PCDF, both removal efficiencies and vapor pressure declined with increasing chlorination. The results of PCDF removal were in consistent with other studies (Chang et al., 2002; Karademir et al., 2004). The PCDD removals, however, showed the opposite trend with that of the above literature. Further studies are needed to identify the discrepancy.

The traditional ACI tests showed that the highest removal efficiency was $97.7 \%$ with $1000 \mathrm{mg} / \mathrm{m}^{3}$ of activated carbon A injected in the dry fluidized bed (contact time is $2 \mathrm{~s}$ ). In practical projects, activated carbon dosage is far less than $1000 \mathrm{mg} / \mathrm{m}^{3}$ because of the reasons mentioned above, so the highest removal efficiency was $96 \%$. When the TEQ concentration of PCDD/Fs in the flue gas was higher than 5 TEQ $\mathrm{ng} / \mathrm{m}^{3}$ (the lowest emission concentration), the emission standard of $0.1 \mathrm{TEQ} \mathrm{ng} / \mathrm{m}^{3}$ could not be achieved through the traditional ACI process. Therefore, to achieve higher removal efficiency, activated carbon injection method needs to be modified besides increasing the amount of activated carbon, selecting an appropriate activated carbon, and increasing contact time.

\section{PCDD/Fs removal efficiencies of pulse ACI process}

The two methods, namely pulse ACI and continuous ACI, were tested under the same conditions with the same activated carbon dosage to evaluate their efficacies in PCDD/Fs removal. The results are shown in Figure 7.

The removal efficiency of total dioxins increased from 96.9 to $99.7 \%$, and the emissions were reduced by more than $90 \%$ (from 49.62 TEQ $\mathrm{ng} / \mathrm{m}^{3}$ to 1.56 TEQ $\left.\mathrm{ng} / \mathrm{m}^{3}\right)$. 


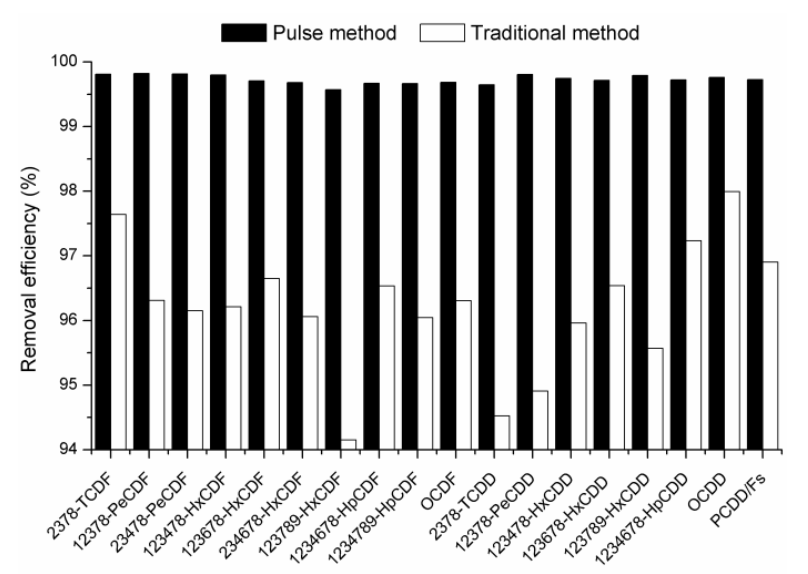

Figure 7. Removal efficiencies of PCDD/F congeners by traditional and pulse method

From Figure 7 it can be seen that for the 17 PCDD/F congeners, PCDD/Fs removal efficiency of pulse ACI method was obviously higher than that of continuous ACI method. The results clearly show that the removal efficiency of dioxins by pulse method was higher than that by continuous method, especially for middle chlorine (4-6) compounds.

The average removal efficiencies of PCDF and PCDD with continuous stable method were nearly same (e.g., 96.2\% and 96.1\%, respectively). The removal efficiencies of both PCDF and PCDD with pulse method were much higher at $99.7 \%$, indicating that modified method was effective for both PCDD and PCDF removal. Removal efficiencies of 17 congeners with pulse method were very consistent while the efficiencies of continuous stable method varied greatly from PCDF to PCDD and with the chlorine content. Since congener profiles and formation mechanism of PCDD/Fs in flue gas are influenced significantly by chlorine content (Wang et al., 2003) and temperature (Mckay, 2002), and high emission of MWIs (medical waste incinerators) may result from non-continuous operations, irregular waste feeding (Choi et al., 2008), and poor operating conditions (WHO, 2011), it is often difficult to maintain stable emission. Hence, the pulse method, which provides relatively stable removal efficiency, has broad application prospects.

As discussed earlier, activated carbon mainly adsorbs dioxins in the gas phase. Taking into account that dioxins and activated carbon are basically maintained at the same flow rate for contact during the continuing activated carbon adsorption process and since the movement between gas and the solid is relatively small and the gas film on the surface of activated carbon is thick, the mass transfer process mainly relies on molecular diffusion. Under such circumstance, the adsorption rate in gas phase is low and thus the utilization of activated carbon. Another drawback is that the activated carbon contained pollutants is enriched on the surface of the bag, increasing the possibility of partial overheating and further release of the pollutants to the flue gas.

Large amount of activated carbon are injected in pulse ACI process in a short time in order to form activated carbon layers on the surface of the bag quickly and then reduce the injection rate, while in continuous ACI process, activated carbon injection rate is constant. The surface of the bag type dust collector also acts as a fixed bed when in contact with flue gas. These two types of activated carbon processes were combined in one system thereby saving the space. Due to different gas and solid velocities, turbulent 
flow occurs in the gas phase thereby reducing the thickness of gas film around the surface of the activated carbon. This results in an improvement in mass transfer efficiency. Moreover, the length of activated carbon layers exceeds the length of the mass transfer zone that prevents penetration at the beginning and the reduction in efficiency. Thus, the inner layer of the activated carbon layer remains relatively cleaned for further purification of the gas through the bag to avoid gaseous phase PCDD/Fs release from the contaminated filters of the aged bag filters because of memory effect (Li et al., 2011).

Studies are being currently conducted focusing on reducing the time of second period which is continuing the PAC adsorption process, in order to reduce the total amount of injected carbon.

\section{Conclusions}

In this study, different influencing factors of traditional ACI method removal efficiency and a developed ACI technology in a medical waste incineration plant were investigated.

Vapor pressures of PCDD/Fs congeners influenced the gas/particle partitioning of PCDD/Fs and dioxin removal efficiencies. The vapor pressure of PCDD/Fs congeners decreases with increasing chlorination and ACI was more effective to remove dioxins in gas phase than in the solid phase.

The removal efficiency could be improved by selecting appropriate adsorption activated carbon species, increasing the dosage of activated carbon, and increasing the gas solid contact time. Activated carbon A was better than B with dosage of 1000 $\mathrm{mg} / \mathrm{m}^{3}$ at a contact time exceeding $8 \mathrm{~s}$.

At the current optimal conditions using the traditional continuously stable activated carbon injection method, average removal efficiency was not high enough to meet the flue gas dioxin emission standards of 0.5 TEQ $\mathrm{ng} / \mathrm{m}^{3}$. Thus, the EU dioxin emission limits in waste incineration of $0.1 \mathrm{TEQ} \mathrm{ng} / \mathrm{m}^{3}$ is very unlikely to be achieved. The pulse activated carbon injection (Pulse ACI) method developed in this study has shown that higher dioxin removal efficiency of $99.7 \%$ than the current traditional method could be obtained, making it possible to achieve the dioxin emission limit of $0.1 \mathrm{TEQ} \mathrm{ng} / \mathrm{m}^{3}$.

Acknowledgements. The authors gratefully acknowledge the support provided by the Shanghai Science and Technology Support Program (09231202702) in China.

\section{REFERENCES}

[1] Abad, E., Caixach, J., Rivera, J. (2003): Improvements in dioxin abatement strategies at a municipal waste management plant in Barcelona. - Chemosphere 50: 1175-1182.

[2] Chang, M. B., Lin, J. J. (2001): Memory effect on the dioxin emissions from municipal waste incinerator in Taiwan. - Chemosphere 45: 1151-1157.

[3] Chang, M. B., Lin, J. J., Chang, S. H. (2002): Characterization of dioxin emissions from two municipal solid waste incinerators in Taiwan. - Atmospheric Environment 36: 279286.

[4] Chen, M. W., Lin, T. C., Wang, L. C., Chang-Chien, G. P. (2014): The PCDD/F removal efficiency of a medical waste incinerator dual-bag filter system. - Aerosol \& Air Quality Research 14: 1223-1231. 
[5] Chi, K. H., Chang, S. H., Chang, M. B. (2008): Reduction of dioxin-like compound emissions from a waelz plant with adsorbent injection and a dual baghouse filter system. - Environmental Science \& Technology 42: 2111-2117.

[6] Choi, K. I., Lee, S. H., Lee, D. H. (2008): Emissions of PCDDs/Fs and dioxin-like PCBs from small waste incinerators in Korea. - Atmospheric Environment 42: 940-948.

[7] Debecker, D. P., Delaigle, R., Hung, P. C., Buekens, A., Gaigneaux, E. M., Chang, M. B. (2011): Evaluation of PCDD/F oxidation catalysts: confronting studies on model molecules with tests on PCDD/F-containing gas stream. - Chemosphere 82: 1337-1342.

[8] Everaert, K., Baeyens, J., Degrève, J. (2003): Entrained phase adsorption of PCDD/F from incinerator flue gases. - Environmental Science \& Technology 37: 1219-1224.

[9] Gunes, G., Saral, A., Yıldız, Ş., Kuzu, S. L. (2015): Determination of optimum dose of adsorbent for PCDD/F removal in the flue gas of a medical waste incineration plant. Chemical Engineering Research \& Design 104: 695-702.

[10] Kim, B. H., Lee, S., Maken, S., Song, H. J., Park, J. W., Min, B. (2007): Removal characteristics of PCDDs/Fs from municipal solid waste incinerator by dual bag filter (DBF) system. - Fuel 86: 813-819.

[11] Karademir, A., Bakoglu, M., Taspinar, F., Ayberk, S. (2004): Removal of PCDD/Fs from flue gas by a fixed-bed activated carbon filter in a hazardous waste incinerator. Environmental Science \& Technology 38: 1201-1207.

[12] Li, H. W., Lee, W. J., Tsai, P. J., Mou, J. L., Chang-Chien, G. P., Yang, K. T. (2008): A novel method to enhance polychlorinated dibenzo-p-dioxins and dibenzofurans removal by adding bio-solution in EAF dust treatment plant. - Journal of Hazardous Materials 150: 83-91.

[13] Li, H. W., Wang, L. C., Chen, C. C., Yang, X. Y., Changchien, G. P., Wu, E. M. (2011): Influence of memory effect caused by aged bag filters on the stack PCDD/F emissions. Journal of Hazardous Materials 185: 1148-1155.

[14] Lin, W. Y., Wang, L. C., Wang, Y. F., Li, H. W., Chang-Chien, G. P. (2008): Removal characteristics of PCDD/Fs by the dual bag filter system of a fly ash treatment plant. Journal of Hazardous Materials 153: 1015-1022.

[15] Mckay, G. (2002): Dioxin characterisation, formation and minimisation during municipal solid waste (MSW) incineration: review. - Chemical Engineering Journal 86: 343-368.

[16] MEP (Ministry of Environmental Protection of China) (2001): Pollution control standard for hazardous waste incineration. - Reference No. GB18484-2001 (in Chinese).

[17] Ooi, T. C., Ewan, B. C., Cliffe, K. R., Anderson, D. R., Fisher, R., Thompson, D. (2008): Removal of vapour phase PCDD/Fs in electric arc furnace steelmaking emissions by sorption using plastics. - Chemosphere 73: 84-89.

[18] Singh, S., Prakash, V. (2007): Toxic environmental releases from medical waste incineration: a review. - Environ Monit Assess 132: 67-81.

[19] Schecter, A., Birnbaum, L., Ryan, J. J. et al. (2006): Dioxins: an overview. Environmental Research 101: 419-428.

[20] Tejima, H., Nakagawa, I., Shinoda, T. A., Maeda, I. (1996): PCDDs/PCDFs reduction by good combustion technology and fabric filter with/without activated carbon injection. Chemosphere 32: 169-175.

[21] Wang, L. C., Lee, W. J., Lee, W. S., Chang-Chien, G. P., Tsai, P. J. (2003): Effect of chlorine content in feeding wastes of incineration on the emission of polychlorinated dibenzo-p-dioxins/dibenzofurans. - Science of the Total Environment 302: 185-198.

[22] WHO (World Health Organization) (2011): Health-care waste management. http://www.who.int/mediacentre/factsheets/fs281/en/ (April 19, 2015). 